\title{
Leukokinetic Studies. IX. Experimental Evaluation of a Model of Granulopoiesis *
}

\author{
D. R. Boggs, $\dagger$ J. W. Athens, G. E. Cartwright, and M. M. Wintrobe \\ (From the Department of Medicine, University of Utah College of Medicine, \\ Salt Lake City, Utah)
}

Kinetic models of granulopoiesis have been constructed from data obtained by labeling neutrophilic granulocytes with tritiated thymidine $(1,2)$, with radioactive phosphorus $(3)$, and with diisopropyl fluorophosphate $\left(\mathrm{DFP}^{32}\right)$ (4). In many respects these models are remarkably similar in their portrayal of the concatenated compartments of normal granulopoiesis. However, certain questions, particularly concerning the structure of the proliferating compartment of the marrow, remain unresolved.

Our experiments were designed to test the validity of several of the assumptions in the model proposed by Warner and Athens (4), which is based on the interpretation of the three phases in the $\mathrm{DFP}^{32}$ curve obtained in normal human subjects. This model has the advantage of adequately describing the data curves obtained from tritiated thymidine and radioactive phosphorus labeling as well as from $\mathrm{DFP}^{32}$ labeling.

Dogs were used in these studies since certain of the experiments could not be carried out in human subjects. The blood granulocyte specific activity (BGSA) curve obtained following injection of $\mathrm{DFP}^{32}$ was determined in normal dogs, and the effect upon this curve of changes in the system induced by vinblastine sulfate, endotoxin, cortisone, and infection has been assessed. Although we previously have reported certain studies on canine cells labeled in vitro with $\mathrm{DFP}^{32}$ (5), most of the studies on the suitability of $\mathrm{DFP}^{32}$ as a cell label have been carried out with cells from human subjects (6). Therefore, it is necessary to describe briefly additional studies of the suitability of $\mathrm{DFP}^{32}$ as a label for dog cells.

\footnotetext{
* Submitted for publication June 15, 1964; accepted December 24, 1964.

This investigation was supported by research grant AM-04489 from the National Institute of Arthritis and Metabolic Diseases, Bethesda, Md.

$\dagger$ Leukemia Society Scholar.
}

\section{Methods}

Animals. Dogs of either sex and weighing from 9 to 32 $\mathrm{kg}$ were given antihelminthic therapy and distemper vaccine and observed for 10 days before use. All studies were done in unanesthetized animals.

Labeling procedures. Tritiated DFP $\left(\mathrm{H}^{3}-\mathrm{DFP}\right)$ and DFP $^{32}$ were obtained commercially. 1 The specific activity of $\mathrm{DFP}^{32}$ was approximately $200 \mu \mathrm{c}$ per $\mathrm{ml}$, and the concentration of $\mathrm{DFP}^{32}$ in propylene glycol diluent was approximately $1 \mathrm{mg}$ per $\mathrm{ml}$. Each batch of material was assayed in our laboratory (6). $\mathrm{DFP}^{32}$ was injected rapidly into a foreleg vein. To evaluate the effect of different dosages upon the configuration of the BGSA curve, $\mathrm{DFP}^{32}$ in amounts ranging from $0.02 \mathrm{mg}$ per $\mathrm{kg}$ to $0.4 \mathrm{mg}$ per $\mathrm{kg}$ was given to groups of dogs. The initial BGSA was directly proportional to the dosage of $\operatorname{DFP}^{32}(r=0.78)$, and no alteration in curve configuration was observed over this range of dosage. Therefore, except as otherwise noted, in subsequent studies $4.5 \mathrm{mg}$ of $\mathrm{DFP}^{32}$ was given to each dog, since this amount resulted in suitable radioactivity levels. In certain of the studies, blood was labeled in vitro and returned to the circulation of the donor (5). All blood samples for leukocyte isolation and determination of specific activity were obtained by jugular puncture.

The techniques of separating dog granulocytes from whole blood and determining their specific activity (counts per minute per milligram leukocyte nitrogen) have been reported (5).

Radioautographs were prepared by incubating $1 \mathrm{ml}$ of blood or aspirated sternal marrow for 1 hour with $1 \mu \mathrm{g}$ of $\mathrm{H}^{3}$-DFP, $256 \mathrm{mc}$ per mmole. Radioautographs of blood and bone marrow were also prepared following the intravenous administration of $4.5 \mathrm{mg}$ of $\mathrm{H}^{3}-\mathrm{DFP}$. All smears were fixed in methanol, dipped in Kodak NTB-2 emulsion, developed after 1 to 5 months of exposure, and stained with Wright's stain. Net grains per cell were determined by subtracting from the number of grains in the individual cell, the mean number of grains in 500 cellfree areas of the slide, of the same size as the cell under study.

Initial labeling conditions. Neutrophilic granulocytes were the only leukocytes that were labeled when blood was incubated in vitro with $\mathrm{H}^{3}$-DFP (Figure 1).

When bone marrow was incubated in vitro with $\mathrm{H}^{3}$ DFP (Table I), the relative degree of labeling was as

${ }^{1}$ New England Nuclear Corp., Boston, Mass. 


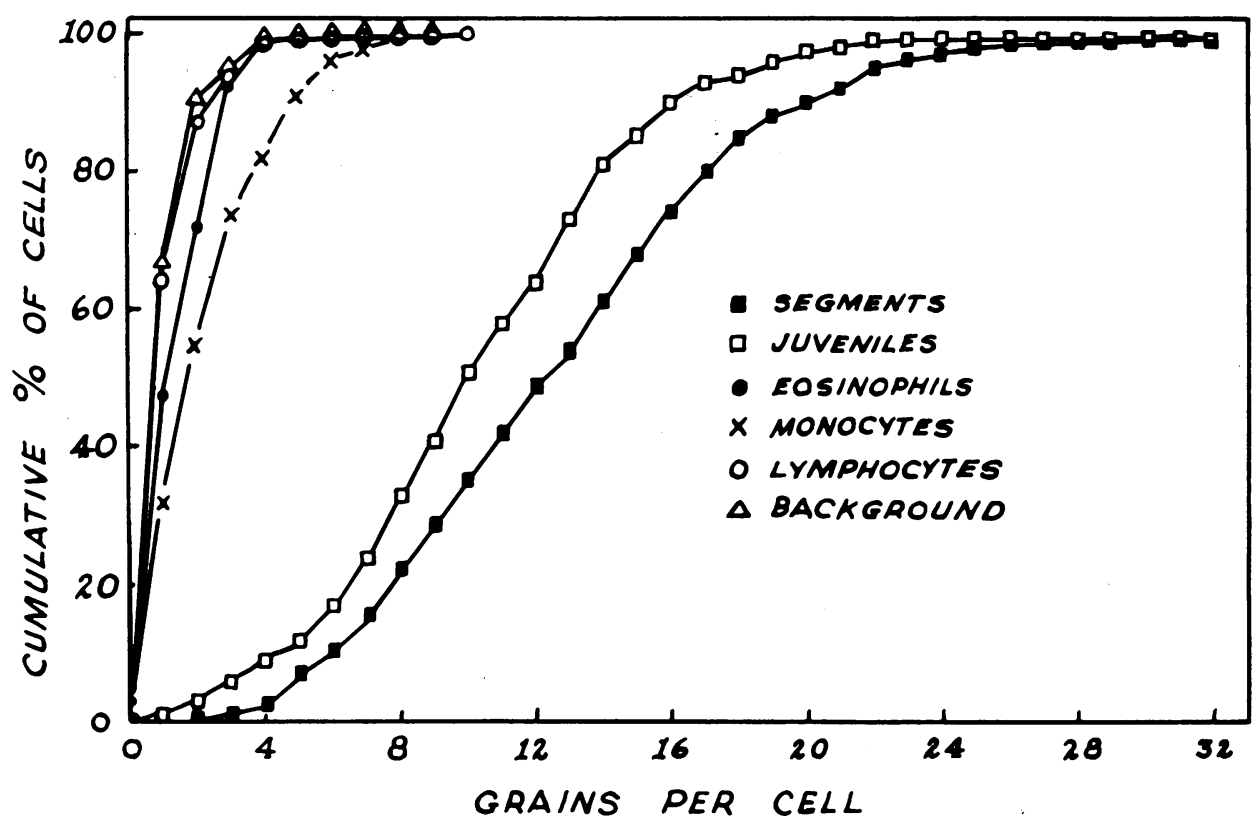

Fig. 1. THE DEgreE OF LABELING OF VARIOUS TYPES OF BLOOD GRANULOCYTES BY TRITIATED DIISOPROPYL FLUOROPHOSPHATE (DFP). The number of grains in 500 segmented neutrophils, juvenile neutrophils, monocytes, and lymphocytes and in 200 eosinophils in one smear from blood incubated in vitro with $\mathrm{H}^{3}-\mathrm{DFP}$ was averaged. Background radioactivity was determined by counting 500 cell-free areas of a size equal to that of the cells counted.

follows: segmented neutrophils, 1.0 ; juvenile neutrophils, 0.93 ; metamyelocytes, 0.73 ; myelocytes, 1.59 ; promyelocytes, 0.09 ; and myeloblasts, 0.09 .

When $\mathrm{H}^{3}$-DFP was injected intravenously, the relative degree of labeling of the myeloid cells in the bone marrow was similar to that observed following the in vitro labeling of marrow cells although the absolute degree of labeling was less. The relative degree of labeling of blood segmented neutrophils : marrow segmented neutrophils: marrow myelocytes was $1: 0.8: 1.4,4$ hours after the injection of $\mathrm{H}^{3}$-DFP.

The time during which DFP is available for labeling was evaluated by injecting $4.5 \mathrm{mg}$ of $\mathrm{DFP}^{32}$ intravenously into four dogs. Blood was removed from the dogs 0.5 , 2 , and 4 hours later. Plasma was separated and incubated with unlabeled whole blood. Granulocytes isolated from the 0.5 -hour plasma mixture contained a barely detectable label, and granulocytes isolated from the 2and 4-hour plasma mixtures contained no label. Thus, the availability time of $\mathrm{DFP}^{32}$ for labeling is 0.5 hours or less.

Evaluation of the labeling method. The leukocyte isolates were essentially free of erythrocytes and platelets by morphologic criteria. However, to determine what if any radioactivity was contributed to the final leukocyte isolate by labeled erythrocytes or pieces of erythrocytes, labeled platelets or pieces of platelets, or labeled plasma, the following studies were performed.

The specific activity of isolated erythrocytes and platelets and of plasma was compared to that of leukocytes in four dogs for a 3-week period following administration of $\mathrm{DFP}^{32}$. The specific activity of erythrocytes, platelets, or plasma rarely exceeded $10 \%$ of the specific activity of leukocytes, and their curve of decline in specific activity differed in configuration from that of leukocytes. In addition, erythrocytes, platelets, and plasma, labeled with $\mathrm{DFP}^{32}$ both in vivo and in vitro, were added to unlabeled whole blood and leukocytes separated from the mixture. These leukocytes isolated did not contain significant radioactivity.

Peritoneal exudates were induced in four dogs during phase IV of the BGSA curve, and the specific activities of leukocyte isolates from blood and exudate were compared. If non-neutrophil sources of radioactivity were contaminating blood leukocyte isolates, then the degree of contamination should have been different in exudate leukocyte isolates. The mean specific activity of exudate leukocytes (198 cpm per $\mathrm{mg} \mathrm{N}$ ) did not differ significantly from that of blood leukocytes (187 cpm per $\mathrm{mg}$ $\mathrm{N})$. The ratio of neutrophils to lymphocytes, monocytes, and eosinophils was ten times greater in the exudate than it was in blood. A few erythrocytes were present in the exudate $\left(12,000\right.$ per $\left.\mathrm{mm}^{3}\right)$, but the specific activity of exudate leukocyte isolates was essentially the same when measured before and after erythrocyte lysis (mean SA of 205 and $198 \mathrm{cpm}$ per $\mathrm{mg} \mathrm{N}$, respectively).

Methylprednisolone, $40 \mathrm{mg}$, and endotoxin, $4 \mu \mathrm{g}$, were given intravenously to groups of dogs during phase IV of the BGSA curve. If lymphocytes, monocytes, or eosinophils were contributing radioactivity to the leukocyte 
TABLE I

Grain counts* over marrow neutrophils and marrow neutrophil precursors after in vitro incubation with $H^{3}-D F P$

\begin{tabular}{|c|c|c|c|c|}
\hline \multirow[b]{3}{*}{ Type of cell } & \multirow{2}{*}{\multicolumn{2}{|c|}{ Net $\dagger$ grain count }} & \multicolumn{2}{|c|}{$\begin{array}{l}\% \text { of cells with grain } \\
\text { counts above background }\end{array}$} \\
\hline & & & \multirow{2}{*}{$\begin{array}{c}\text { Above } \\
\text { highest } \\
\text { background } \dagger\end{array}$} & \multirow{2}{*}{$\begin{array}{c}\text { More than } \\
10 \text { grains } \\
\text { above } \\
\text { highest } \\
\text { background }\end{array}$} \\
\hline & Mean & Range & & \\
\hline $\begin{array}{l}\text { Polymorphonuclear } \\
\text { Juvenile } \\
\text { Metamyelocyte } \\
\text { Myelocyte } \\
\text { Promyelocyte } \\
\text { Myeloblast }\end{array}$ & $\begin{array}{r}29.2 \\
27.3 \\
21.4 \\
46.5 \\
2.7 \\
2.7\end{array}$ & $\begin{array}{l}7-63 \\
6-58 \\
0-47 \\
6-126 \\
0-48 \\
0-18\end{array}$ & $\begin{array}{l}99.4 \\
98.6 \\
94.0 \\
98.8 \\
8.2 \\
8.5\end{array}$ & $\begin{array}{l}83.8 \\
77.8 \\
70.6 \\
92.0 \\
2.0 \\
0\end{array}$ \\
\hline
\end{tabular}

* Mean grain count for polymorphonuclear, juvenile, metamyelocyte, myelocyte, and promyelocyte determined by counting 500 of each type of cell and for myeloblast by counting 200 cells.

$\dagger$ Background determined from counting 500 blank areas on the slide equivalent in size to the cell in question. Net grain count determined by subtracting mean background from gross cellular grain count.

isolate, administration of these drugs, which markedly reduce the concentration of these cells in blood, should reduce their contribution. Before prednisolone or endotoxin, the mean BGSA was $381 \mathrm{cpm}$ per $\mathrm{mg} \mathrm{N}$, and BGSA was not significantly different (399 cpm per mg N) 4 hours after these drugs were administered.

Thus, no evidence was obtained to suggest that any non-neutrophil source was contributing radioactivity to BGSA measurements.

Although no evidence has been obtained that $\mathrm{DFP}^{22}$ elutes from or damages human granulocytes (6), several studies were done to investigate the possibility that DFP $^{32}$ elutes from or damages canine granulocytes. Blood samples were allowed to stand at room temperature for varying periods of time, and isolated granulocytes were washed four, five, or six times. These procedures had no influence on the specific activity of the granulocytes that were isolated. It would be expected that if $\mathrm{DFP}^{32}$ elutes from or damages granulocytes, the degree of elution or damage might increase as the amount of label in the cell increases. As mentioned above, it was found that over a 20 -fold range in DFP ${ }^{32}$ dosage, the initial level of BGSA was directly proportional to the amount of DFP administered, and the configuration of the curves was unaltered. Two dogs were each given four injections of $4.5 \mathrm{mg}$ of $\mathrm{DFP}^{32}$ at 3 -day intervals. The specific activity of the blood granulocytes increased after each injection, and the configuration of the curve following the fourth injection was similar to that which followed a single injection. To determine if labeled cells behaved functionally like unlabeled cells, a peritoneal exudate was induced in four dogs. The specific activity of the cells in the exudate was not significantly different from the specific activity of the cells in the blood.

The possibility that a metabolite of a DFP ${ }^{32}$-labeled protein is reutilized was explored by measuring the proportion of granulocyte radioactivity extractable with protein or with lipid. This was done during the first week after the administration of $\mathrm{DFP}^{32}$ and again during the third week after labeling (Table II). The method of
Folch, Lees, and Stanley (7) was used for lipid extraction. The method of Jandorf and McNamara (8) was used for protein extraction. The proportion of radioactivity extractable with lipid increased with time. The proportion extractable with protein decreased with time.

No untoward effects of DFP ${ }^{32}$ administration (6) were observed in any of the dogs. The mean granulocyte count in the group of 14 dogs used to establish the normal BGSA curve was 11,800 per $\mathrm{mm}^{3}$ with a determined range of 6,000 to 18,000 . Blood granulocyte values were measured three to seven times per week in each dog. No consistent changes were observed as a consequence of the procedure. Sternal marrow differential counts both before and 1 week after the administration of DFP ${ }^{20}$ were as follows (mean values in per cent of total myeloid cells counted): myeloblasts, 1 ; promyelocytes, 5 ; myelocytes, 15; metamyelocytes, 37; juvenile neutrophils, 37; and segmented neutrophils, 5.

\section{Results}

\section{Control BGSA curve}

Fourteen dogs were given $4.5 \mathrm{mg}$ of $\mathrm{DFP}^{32}$, and the BGSA was determined $1,3,6$, and 10 hours later, at daily intervals thereafter for 2

TABLE II

Fractionation of granulocyte radioactivity

\begin{tabular}{lcc}
\hline \hline & \multicolumn{2}{c}{$\%$ of total radioactivity in } \\
\cline { 2 - 3 } & Protein & Lipid \\
\hline $\begin{array}{l}\text { During first } \\
\text { week after DFP }\end{array}$ & 94 & 3 \\
$\begin{array}{l}\text { During third } \\
\text { week after DFP }\end{array}$ & $(61-115)^{*}$ & $(1-5)$ \\
\hline
\end{tabular}

* Figures in parentheses refer to range. 
TABLE III

The blood granulocyte specific activity (BGSA) curve in control dogs and in dogs given vinblastine sulfate $(V L B)$, cortisone, and endotoxin and with infertion

\begin{tabular}{|c|c|c|c|c|c|c|}
\hline & & \multirow[b]{2}{*}{$\begin{array}{l}\text { No. of } \\
\text { dogs }\end{array}$} & \multicolumn{4}{|c|}{ Phases in BGSA curve } \\
\hline & & & $\underset{\text { duration }}{\text { I + II }}$ & $\mathrm{III}_{\mathrm{t}_{\frac{1}{2}}}$ & $\underset{\text { intercept }}{\text { III-IV }}$ & $\begin{array}{l}\text { IV } \\
\text { slope }\end{array}$ \\
\hline & & & days & hrs & $\begin{array}{c}{ }_{B G S A} \text { of } T_{0} * \\
\text { B }\end{array}$ & $\begin{array}{c}\text { \% decrease/ } \\
\text { day }\end{array}$ \\
\hline Control & Mean $\dagger$ & 14 & $\begin{array}{l}4.8 \\
(3.0-7.1)\end{array}$ & $\begin{array}{c}46 \\
(32-60)\end{array}$ & $\begin{array}{c}16 \\
(8-30)\end{array}$ & $\begin{array}{c}3.7 \\
(1-7)\end{array}$ \\
\hline \multicolumn{7}{|l|}{$\begin{array}{l}\text { Vinblastine sulfate } \\
\text { Given: }\end{array}$} \\
\hline $\mathrm{DFP}^{32} 1 \mathrm{hr}$ before VLB & Mean & 8 & $\begin{array}{c}3.4 \S \\
(1.0-4.5)\end{array}$ & $\begin{array}{c}21 \S \\
(14-27)\end{array}$ & $\begin{array}{c}13 \\
(6-23)\end{array}$ & $\begin{array}{c}4.0 \\
(0-10)\end{array}$ \\
\hline $\mathrm{DFP}^{32} 2$ days after VLB & Mean & 4 & $\begin{array}{c}2.3 \S \\
(1.0-4.0)\end{array}$ & $\begin{array}{c}24 \S \\
(12-33)\end{array}$ & $\begin{array}{c}24 \\
(10-43)\end{array}$ & $\begin{array}{c}2.0 \\
(1-3)\end{array}$ \\
\hline $\mathrm{DFP}^{32} 6$ days after VLB & Mean & 5 & $\stackrel{4.6}{(3.5-6.0)}$ & $\stackrel{42}{(25-76)}$ & $\begin{array}{c}21 \\
(10-45)\end{array}$ & $\begin{array}{c}1.8 \\
(1-3)\end{array}$ \\
\hline DFP $^{32} 14$ days after VLB & Mean & 4 & $\begin{array}{l}7.0 \S \\
(6.5-7.5)\end{array}$ & $\begin{array}{c}24 \S \\
(16-31)\end{array}$ & $\begin{array}{c}10 \\
(5-13)\end{array}$ & $\begin{array}{l}2.2 \\
(1-5)\end{array}$ \\
\hline \multicolumn{7}{|l|}{ Endotoxin } \\
\hline $\begin{array}{l}\text { Given } 1 \text { hr or } 2 \text { days after } \\
\text { DFP }^{32}\end{array}$ & Mean & 8 & $\begin{array}{l}3.7 \S \\
(3.0-5.3)\end{array}$ & $\begin{array}{c}35 \S \\
(27-51)\end{array}$ & $\begin{array}{c}22 \\
(12-48)\end{array}$ & $\begin{array}{c}2.5 \\
(0-12)\end{array}$ \\
\hline \multicolumn{7}{|l|}{ Cortisone acetate } \\
\hline $\begin{array}{l}\text { Given daily, starting } 5 \\
\text { days before DFP }\end{array}$ & Mean & 5 & $\begin{array}{l}4.4 \\
(4.0-5.0)\end{array}$ & $\begin{array}{c}40 \\
(35-47)\end{array}$ & $\stackrel{9}{9}$ & $\begin{array}{r}2.8 \\
(1-4)\end{array}$ \\
\hline \multicolumn{7}{|l|}{ Pulmonary infections } \\
\hline \multicolumn{7}{|l|}{$\operatorname{Dog} 131$} \\
\hline $\begin{array}{l}\text { During infection } \\
\text { After recovery }\end{array}$ & & & $\begin{array}{l}2.4 \\
4.3\end{array}$ & $\begin{array}{l}20 \\
48\end{array}$ & $\begin{array}{l}20 \\
22\end{array}$ & $\begin{array}{l}3.2 \\
2.5\end{array}$ \\
\hline \multicolumn{7}{|l|}{ Dog 122} \\
\hline During infection & & & 2.3 & 28 & 12 & 2.2 \\
\hline
\end{tabular}

* $\mathrm{T}_{\text {}}$ refers to the initial BGSA determination, done 1 to 3 hours after administering DFP ${ }^{32}$.

$\dagger$ Numbers in parentheses refer to ranges.

$\$$ Dogs that developed diarrhea (9) were excluded from this analysis.

$\S$ Differs from normal with $\mathrm{p}=<0.05$ by $t$ test.

weeks, and then three to five times a week for a total period of study of at least 4 weeks. The resultant mean curve is presented in Figure 2. On a milligram per kilogram basis, this dosage averaged 15 times that given to man (6). This large dose in the dog proved necessary to attain an initial BGSA comparable to that attained in man.

Four phases could be distinguished. During the first day the BGSA declined 20\% (phase I). The specific activity of the granulocytes then remained relatively stable, declining only $2 \%$ per day, until the fifth day (phase II). This was followed by a rapid exponential decline in BGSA (phase III). Finally, the slope of the curve slowed abruptly to a mean decline of $4 \%$ per day (phase IV).
The mean and the range of the duration of phase I + II, the $t_{\frac{1}{2}}$ of phase III, the level at which the phase III-IV intercept occurred, and the slope of phase IV are given in Table III. A significant inverse relationship was found between the duration of phase $I+I I$ and the $t_{1}$ of phase III in these studies on normal animals $(\mathrm{r}=-0.82, \mathrm{p}=<0.001)$.

\section{Effect of vinblastine sulfate (VLB)}

Dogs were given $\mathrm{DFP}^{32}$ at four different times in relation to administration of $0.2 \mathrm{mg}$ per $\mathrm{kg}$ of VLB : 1 hour before VLB to eliminate the contribution of the mitotic pool to the BGSA curve, 2 days after VLB to determine the effect of a decreased mitotic pool and a reduced number of 


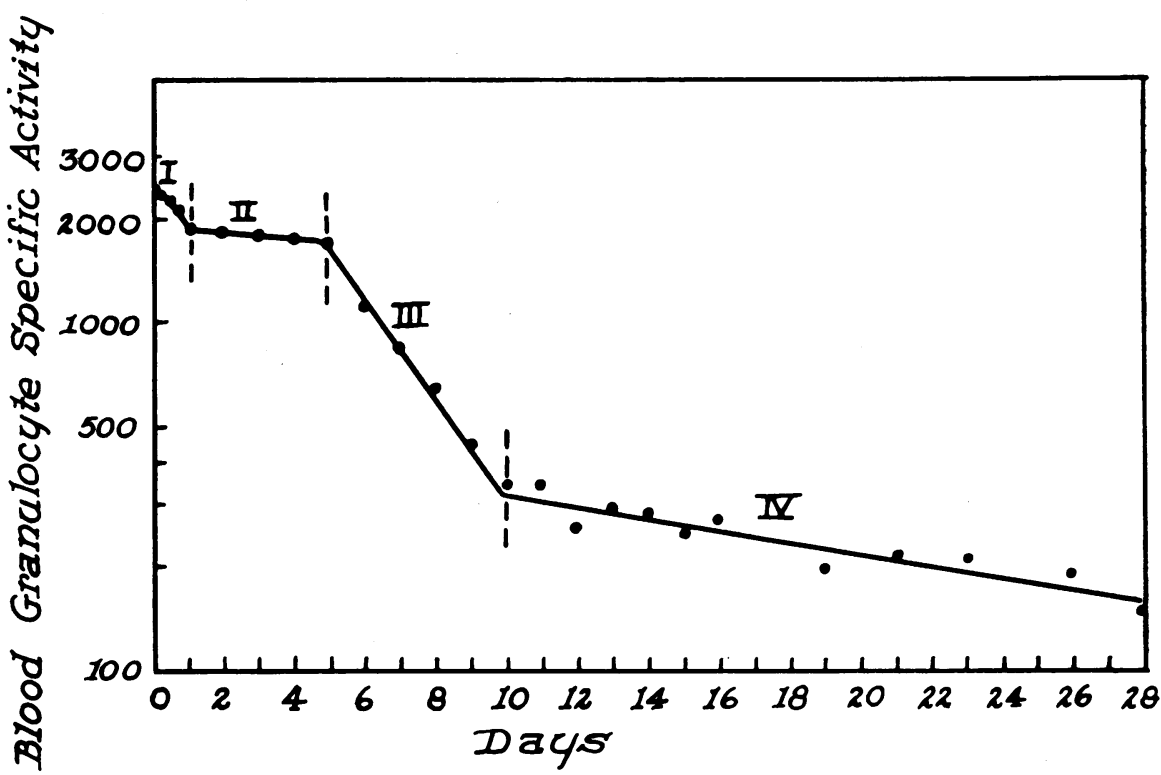

Fig. 2. The mean blood granulocyte specific activity CURVE for 14 NoRmal dogs GIVEN $4.5 \mathrm{MG} \mathrm{DFP}^{32}$. The duration of phase I + II was determined from the intercept point of the best line through phase II and phase III. The starting point of phase IV was determined by the intercept of the best line through phase III and phase IV.

postmitotic cells upon the curve, 6 days after VLB to study the BGSA curve in a rapidly regenerating system, and 14 days after VLB to study the curve at a time when the granulocyte count was increased greatly and the entire system presumably was hypertrophied. The effect of this dosage of VLB upon blood granulocyte concentration, proportion of marrow myelocytes, and the BGSA curve is illustrated in Figure 3. Blood granulocyte concentration did not change significantly for 3 days, decreased precipitously on the fourth day, began to increase toward normal on the sixth day, and then increased to values above the initial control value. The proportion of myelocytes in the bone marrow (expressed as percentage of total granulocytes and granulocyte precursors) decreased from a control value of $13.6 \%$ to $1.4 \%$ within 1 day following administration of VLB (a $90 \%$ reduction). This figure of $90 \%$ is an underestimate of the absolute degree of myelocyte reduction, for the day 1 figure represents percentage of a smaller total granulocyte mass than does the control figure. Pertinent characteristics of the BGSA curves obtained at different times in relation to administration of VLB are summarized in Table III.
Phase I + II was reduced from the normal value of 4.8 days to 3.4 days in the dogs given DFP $^{32} 1$ hour before VLB. The $t_{\frac{1}{2}}$ of phase III was shortened from 46 to 21 hours, and phase IV was not altered significantly. In the dogs given DFP $^{32} 2$ days after VLB, phase I + II was shortened from 4.8 to 2.3 days, the $t_{1}$ of phase III was decreased from 46 to 24 hours, and phase IV was not influenced. The values were within normal limits when DFP was given 6 days after VLB. When $\mathrm{DFP}^{32}$ was given 14 days after VLB, phase I + II was increased to 7.0 days, the $t_{\frac{1}{2}}$ of phase III was 24 hours, and phase IV was not altered to a significant degree.

The blood granulocyte turnover rate (GTR) was determined in four dogs before they were given VLB and 2 and 14 days after they were given VLB (Table IV). Two days after VLB the mean GTR was not changed significantly from control values, but 14 days after VLB the mean GTR was greater than the control value.

\section{Effect of endotoxin}

Four dogs were given $4 \mu \mathrm{g}$ of bacterial endotoxin intravenously 1 hour after $\mathrm{DFP}^{32}$. Four 


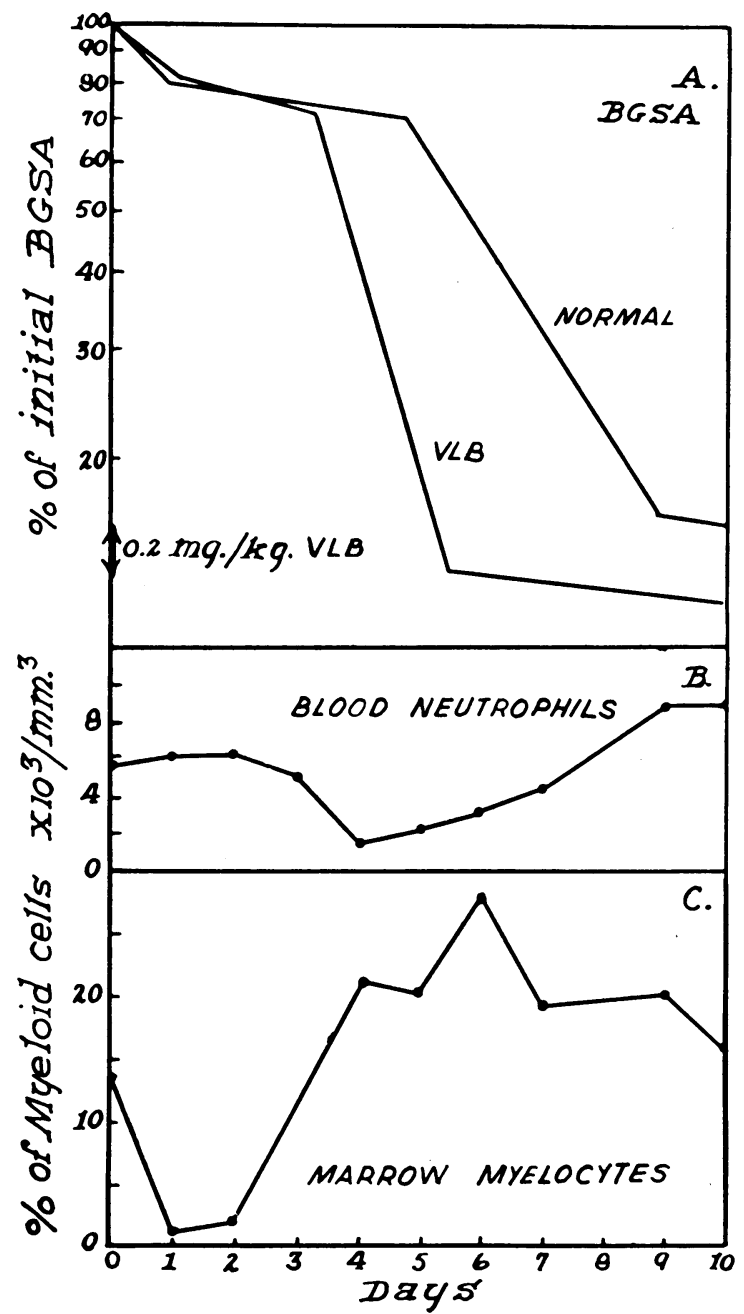

Fig. 3. The effect of vinblastine sulfate UPON THE BLOOD GRANULOCYTE SPECIFIC ACTIVITY CURVE (A), BLOOD NEUTROPHIL CONCENTRATION (B), AND PROPORTION OF MYELOCYTES IN BONE MARROW (C).

other dogs were given the same amount 2 days after $\mathrm{DFP}^{32}$. Since the effect on the BGSA curve of endotoxin given at these two times was the same, the results in the two groups are combined in Table III.

Phase I + II was reduced from the normal value of 4.8 to 3.7 days. The $t_{1}$ of phase III was reduced from 46 to 35 hours. The increase in the phase III-IV intercept was not statistically significant $(\mathrm{p}=<0.5)$.

\section{Effect of cortisone}

Cortisone acetate, $125 \mathrm{mg}$ per day, was administered intramuscularly to 12 dogs. A sus- tained granulocytosis developed in all dogs (Table IV).

The GTR was studied before and after 7 days of cortisone administration in seven dogs (Table IV). As demonstrated previously in man (10), the GTR was within normal limits during cortisone-induced granulocytosis.

On the seventh day of cortisone, $\mathrm{DFP}^{32}$ was given intravenously to five dogs, the cortisone was continued, and the BGSA curve was determined. The resultant BGSA curve was within normal limits (Table III).

\section{Effect of spontaneously occurring infection}

Three dogs developed infection characterized by cough, purulent nasal discharge,-signs of pulmonary consolidation, and granulocytosis. This provided an opportunity to study the influence of infection on the BGSA curve.

Dog 131 was first studied while acutely ill. During the period of this study the granulocyte count ranged from 21,000 to 36,000 per $\mathrm{mm}^{3}$. Two months after the illness had subsided, at which time the granulocyte count was normal $\left(10,000\right.$ per $\left.\mathrm{mm}^{3}\right)$ and remained so, a second BGSA curve was obtained (Table III). During the acute illness, phase I + II was decreased, and the $t_{1}$ of phase III was only 20 hours. After recovery the BGSA curve was within normal limits.

The illness in dog 122 was severe and eventually fatal. The granulocyte count increased progressively and attained a value of 44,000 per $\mathrm{mm}^{3}$ at the time of death. $\mathrm{DFP}^{32}$ was given intravenously 16 days before death at which time the granulocyte count was 15,000 per $\mathrm{mm}^{3}$. As in $\operatorname{dog} 131$, phase I + II was shortened, and the $t_{z}$ of phase III was decreased (Table III).

$\mathrm{DFP}^{32}$ had been given to $\operatorname{dog} 3$ as a normal control (Figure 4). In this animal the apparent onset of the illness occurred after phases I, II, and III had been completed. The development of profound granulocytosis had no influence on the slope of phase IV.

\section{Interpretation of the four phases of the BGSA curve}

From the initial labeling conditions determined with $\mathrm{H}^{3}$-DFP and from information that is avail- 


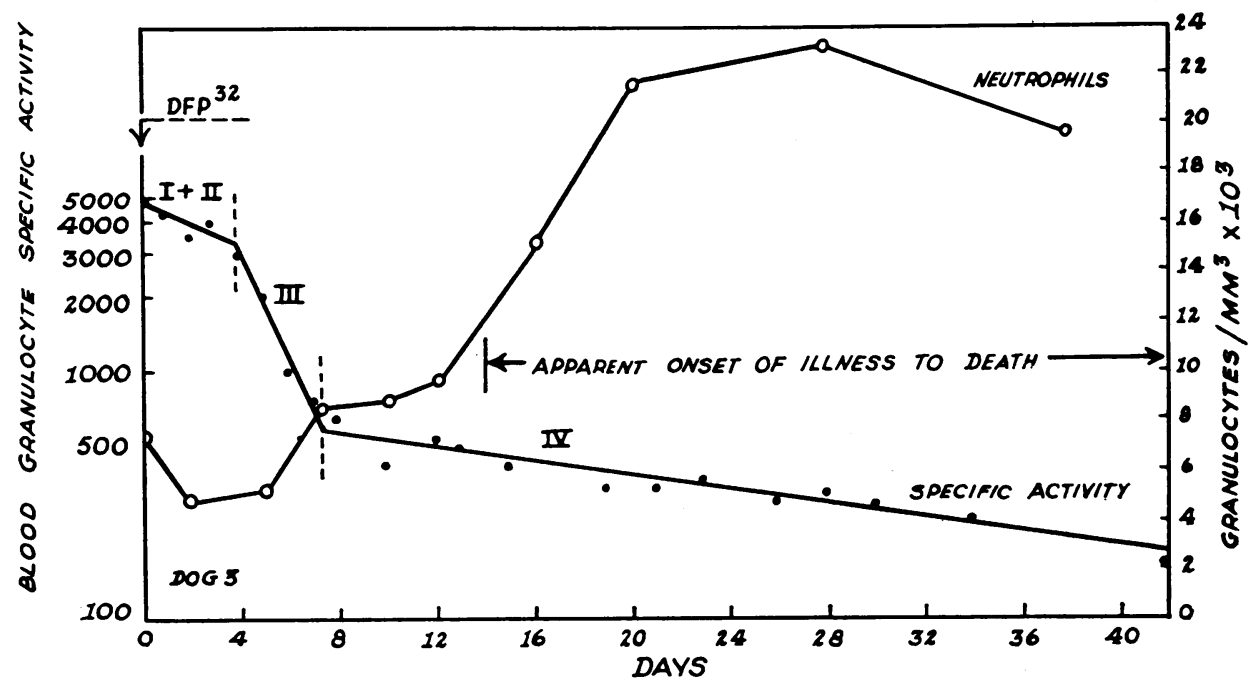

Fig. 4. THE FAILURE OF MARKed GRANULOCYTOSIS ACCOMPANYING INFECTION TO INFLUENCE THE CONFIGURATION OF PHASE IV.

able concerning the mechanisms by which VLB (9), endotoxin (10), and cortisone (10) perturb the granulopoietic system, certain deductions can be drawn concerning the interpretation of each of the four phases of the BGSA curve.

Phase I. During phase I the specific activity of the granulocytes declined to $80 \%$ of the initial
$\left(T_{0}\right)$ value. This can be explained by the observation that, after the intravenous administration of $\mathrm{H}^{3}$-DFP, the segmented neutrophils in the blood labeled to a greater degree (relative labeling index of 1.0) than did the segmented neutrophils in the bone marrow (relative labeling index of 0.8 ). Therefore, as the more heavily labeled

TABLE IV

Blood granulocyte turnover rate* (from studies of infused autologous, DFP32-labeled granulocytes) before and after VLB and cortisone

\begin{tabular}{|c|c|c|c|c|c|}
\hline & & $\begin{array}{c}\text { Granulocyte } \\
\text { count }\end{array}$ & $\begin{array}{c}\text { Total blood } \\
\text { granulocyte } \\
\text { pool }\end{array}$ & $t_{3}$ & $\begin{array}{c}\text { Granulocyte } \\
\text { turnover rate }\end{array}$ \\
\hline & & $\stackrel{\operatorname{mm} m^{3} \text { blood }}{\times 10^{3}}$ & $\times 10^{7}$ cells $/ \mathrm{kg}$ & hrs & $\times \begin{array}{l}10^{7} \text { cells } / \\
k g / d a y\end{array}$ \\
\hline \multicolumn{6}{|l|}{$\begin{array}{l}\text { Vinblastine sulfate } \\
\text { (4 dogs) }\end{array}$} \\
\hline Control & Mean $\dagger$ & $\begin{array}{c}6.1 \\
(3.6-10.3)\end{array}$ & $\begin{array}{c}122 \\
(60-191)\end{array}$ & $\begin{array}{c}5.9 \\
(5.4-6.9)\end{array}$ & $\begin{array}{c}335 \\
(185-460)\end{array}$ \\
\hline 2 days post-VLB & Mean & $\begin{array}{c}5.0 \\
(2.6-8.8)\end{array}$ & $\begin{array}{c}148 \\
(49-318)\end{array}$ & $\stackrel{8.0 \ddagger}{(7.1-8.5)}$ & $\begin{array}{c}306 \\
(115-661)\end{array}$ \\
\hline 14 days post-VLB & Mean & $\begin{array}{c}11.2 \ddagger \\
(9.5-12.9)\end{array}$ & $\begin{array}{c}193 \ddagger \\
(125-265)\end{array}$ & $\begin{array}{c}6.1 \\
(4.6-8.6)\end{array}$ & $\begin{array}{c}527 \ddagger \\
(400-747)\end{array}$ \\
\hline \multicolumn{6}{|l|}{$\begin{array}{l}\text { Cortisone } \\
\text { (7 dogs) }\end{array}$} \\
\hline Control & Mean & $\begin{array}{c}5.6 \\
(3.0-8.4)\end{array}$ & $\begin{array}{c}88 \\
(53-112)\end{array}$ & $\begin{array}{c}5.3 \\
(3.8-6.3)\end{array}$ & $\begin{array}{c}301 \\
(157-468)\end{array}$ \\
\hline $\begin{array}{l}\text { On day } 7 \text { of cortisone } \\
\text { administration }\end{array}$ & Mean & $\begin{array}{c}13.8 \ddagger \\
(8.7-30.1)\end{array}$ & $\underset{(67-269)}{162 \ddagger}$ & $\begin{array}{c}7.6 \ddagger \\
(6.0-10.2)\end{array}$ & $\begin{array}{c}352 \\
(136-438)\end{array}$ \\
\hline
\end{tabular}

* Granulocyte turnover rate is defined from studies employing granulocytes labeled in vitro and reinfused. GTR $=\left(.693 / t_{t}\right) \times$ total blood granulocyte pool $\times 24$ hours.

$\dagger$ Numbers in parentheses refer to range.

$\ddagger$ Differs from control value by $\mathrm{p}=<0.05, t$ test. 
neutrophils in the blood were replaced by the less heavily labeled segmented neutrophils from the marrow, the specific activity of the cells in the blood declined to $80 \%$ of the initial value.

This explanation for phase $I$ in the dog is the same as in man. However, there is a greater blood to marrow labeling differential in man (11) than in the dog; in man the specific activity of the cells declines to $27 \%$ of the initial value (4). This difference between dog and man may be due to the less rapid uptake of DFP by dog cells (5) as compared to human cells (6). The difference is not explainable by the larger dosage of $\mathrm{DFP}^{32}$ given to dogs as compared to man, since the configuration of the BGSA curve in the dog was independent of $\mathrm{DFP}^{32}$ dosage.

Phase II. The relative degree of labeling of the myeloid cells within the marrow was as follows: segmented neutrophils, 1.0 ; juvenile neutrophils, 0.93 ; metamyelocytes, 0.73 ; and myelocytes, 1.59. The progeny of the first myelocyte division would be expected to have a relative labeling value of $1.59 / 2$, or 0.79 . Therefore, as segmented neutrophils, juvenile neutrophils, metamyelocytes, and the progeny of the first myelocyte division move sequentially from the bone marrow to the blood, the specific activity of the cells in the blood compartment should decline at a very slow rate. When the progeny of the second myelocyte division reach the blood, a more rapid decline in specific activity should occur. Therefore, the duration of phase I + II, that is, the time from the administration of $\mathrm{DFP}^{32}$ to the time when there is a sharp inflection (onset of phase III) in the curve (Figure 2), must represent the period of time required for a myelocyte to divide, mature, and enter the blood as a segmented neutrophil. This is the same interpretation as given to phase II in the curve in human subjects (4). The interpretation is supported by the data obtained following the administration of VLB, endotoxin, and cortisone to the dog.

It has been shown that VLB in the amount used in these experiments greatly reduces the mitotic cells (myeloblasts, promyelocytes, and myelocytes) in the marrow (9). This agent has no detectable influence on the postmitotic cells (metamyelocytes, juvenile and segmented neutrophils). However, 2 days after VLB has been given, the postmitotic pool of cells would be par- tially depleted because these cells continue to move into the blood and are not replaced by cells from the mitotic pool. Six days after VLB has been given the system is recovering, and 14 days after VLB the granulocyte count in the blood is greater than normal, and presumably the various bone marrow pools are increased in size. Therefore, it would be expected that if $\mathrm{DFP}^{32}$ were given to animals at a time when the myelocytes were incapable of contributing progeny and the postmitotic pool had not yet begun to decrease in size, then the duration of phase I + II should be shortened to the degree that the myelocyte progeny contribute to this phase of the curve. If the $\mathrm{DFP}^{32}$ were given at a time when the postmitotic pool of cells had decreased in size as well, it would be expected that phase I + II would be shortened still further. If the $\mathrm{DFP}^{32}$ were given at a time when the mitotic and postmitotic pool sizes were increased beyond the normal size, it would be expected that the duration of phase I + II would be prolonged. All of these events occurred as anticipated (Table III).

It has been shown by others (12) as well as by ourselves (10) that the granulocytosis following the administration of bacterial endotoxin is due to the rapid influx of cells from the bone marrow. Therefore, it would be expected that the effect of endotoxin on the BGSA curve would be to shorten the duration of phase I + II, and this is what occurred (Table III).

Since cortisone-induced granulocytosis is not associated with an increased granulocyte turnover rate (GTR), it can be concluded that in animals so treated, cells move from the marrow to the blood at a normal rate. Therefore, the observation of phase I + II of normal duration is to be expected (Table III).

Phase III. At least three different factors influence the shape and slope of phase III in man (4). Therefore, it is surprising that this phase appears as an exponential function. It is quite likely that the data points are not so exact as to distinguish an exponential function from one that approximates such a function.

From computer analyses of BGSA curves in human subjects, the generation time of the myelocyte compartment emerged as the critical parameter in determining the slope of phase III (4). The present studies confirm that postulate, for 
when the myelocyte compartment was greatly reduced with VLB, the $t_{\frac{1}{2}}$ of phase III was reduced from 46 to 21 hours (Figure 3, Table III). The contribution of progeny of labeled myelocytes to phase III should represent the difference between the phase III observed in normal dogs and that observed in dogs given DFP $^{32} 1$ hour before or 2 days after VLB. The 21 - to 24 -hour phase III observed in the above groups of post-VLB dogs should represent the contribution to phase III of factors other than labeled myelocyte progeny. Phase III should not begin in these post-VLB dogs until unlabeled cells (produced by myelocytes that have regenerated following VLB-induced myelotoxicity induced after $\mathrm{DFP}^{32}$ labeling) begin to replace labeled blood cells (which were initially in the postmitotic compartment when $\mathrm{DFP}^{32}$ was given). If cells are assumed to move through the postmitotic compartment in a very strict first-in, first-out manner, then the $t_{\frac{1}{2}}$ of phase III in post-VLB dogs should have been 6 hours or less, the blood granulocyte half-disappearance time (5). Since the $t_{\frac{1}{2}}$ of phase III in these post-VLB dogs was much greater than 6 hours, 21 and 24 hours in the two groups, the portion of the slope of phase III in the dog that cannot be attributed to the myelocyte compartment probably represents a summation of at least three factors. The mean blood granulocyte transit time contributes a 6-hour $t_{1}$ to the slope of phase III $(4,5)$. Variation in transit time through the postmitotic marrow compartment influences the slope of phase III (4). Finally, the slope of phase IV must influence phase III.

Theoretically, the slope of phase IV should be subtracted from phase III. If the slope of phase IV is extrapolated back to the beginning of phase III and then subtracted, the $t_{\text {in }}$ in normal dogs becomes 31 hours, and the $t_{\frac{1}{2}}$ in the postVLB dogs becomes 13 hours as compared to uncorrected values of 46 and 21 hours, respectively. The contribution of the myelocyte population becomes 18 hours rather than 25 hours. However, as will be discussed in the section that follows, the shape of the phase IV curve before day 7 is not known, and it is probably incorrect to assume that the slope of phase IV can be extrapolated back toward the ordinate. In either event the qualitative interpretation of the data is not influenced by the contribution of phase IV.
Phase IV. A phase similar to phase IV in the dog has not been observed in man (4), but it should be noted that on a milligram per kilogram basis these dogs were given an average of 15 times more $\mathrm{DFP}^{32}$ than were men.

The unusual feature of this phase in the dog BGSA curve is that it was not significantly influenced by any of the perturbations that were induced. Neither ablation of the mitotic pool nor modification in the duration of phase I + II altered the relative height of the III-IV intercept or the slope of phase IV. Furthermore, the development of a profound granulocytosis in dog 3 (Figure 4) during phase IV did not modify the slope.

Many possible explanations for the occurrence of this phase were considered and investigated, including contamination of the granulocyte radioactivity measurements by labeled erythrocytes, lymphocytes;' monocytes, eosinophils, basophils, platelets, or plasma (discussed in the section on evaluation of the labeling method); a second population of granulocytes with a kinetic pattern distinctly different from the first; return of granulocytes to the blood; and return of granulocytes to bone marrow. However, none of these explanations is compatible with the data presented that give evidence of the purity of the granulocyte isolates and of the degree of labeling of nongranulocytic cells with $\mathrm{H}^{3}$-DFP; nor are they consistent with any of the observations on the perturbed system mentioned above. For example, none of these explanations can account for the persistence of a normal phase IV in the dog in whom fatal infection and marked granulocytosis supervened at the beginning of phase IV (Figure 4). However, if newly forming granulocytes were incorporating a reutilizable compound from $\mathrm{DFP}^{32}$-labeled enzyme breakdown of many tissues, the normal phase IV in this dog can be explained.

The presence of radioactivity in the lipid fraction from granulocytes during phase IV suggests that some $\mathrm{O}$-serine phosphate may be formed as labeled proteins are degraded (13). Incorporation of O-serine phosphate into phospholipids is known to occur through the phosphatidyl serine and phosphatidyl ethanolamine pathways (14 16). Furthermore, O-serine phosphatases are present in tissues (17), and therefore the inor- 


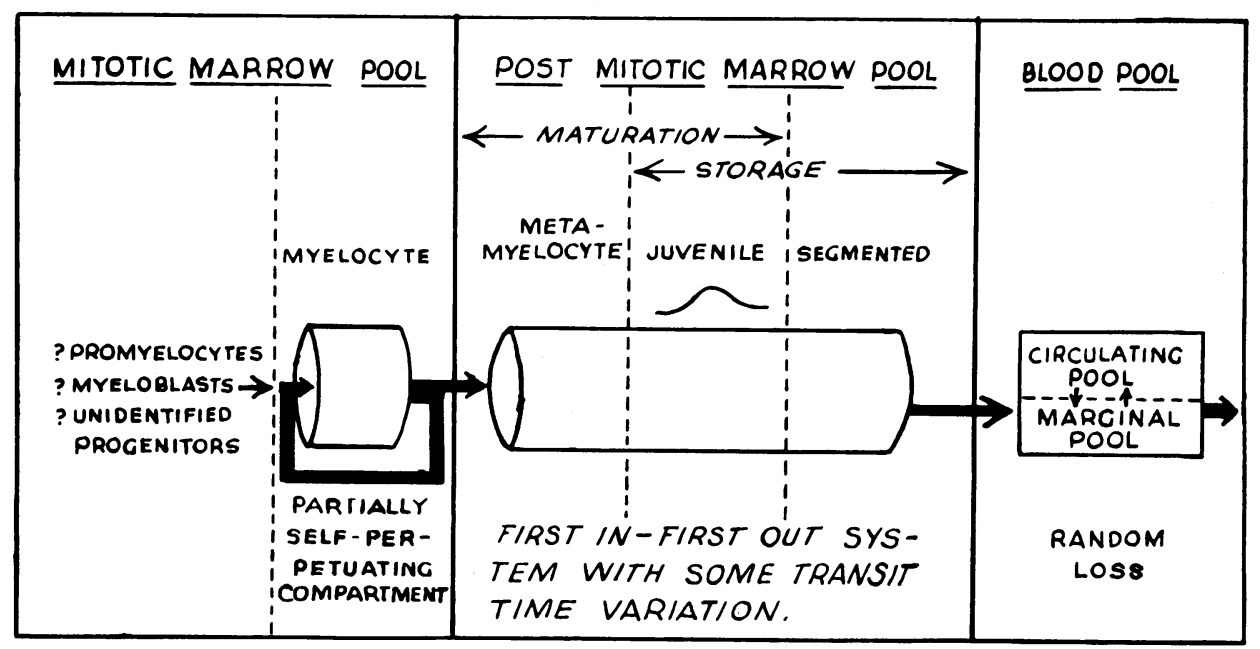

Fig. 5. A MODEL OF GRANULOPOIESIS.

ganic phosphate pool may be labeled as well at this time. Most of the $\mathrm{DFP}^{32}$ that is injected intravenously is bound to tissues other than leukocytes $(8)$; therefore, leukocyte esterases probably constitute a minor source for the labeled degradation products.

\section{Discussion}

We consider that the time required for the myelocyte compartment to complete a generation cycle and for its progeny to mature and enter the blood is measured by the duration of phase I + II, a mean of 4.8 days in normal dogs. A similar measurement is obtained by determining the time at which the most heavily labeled population of cells reaches the blood after selective labeling with tritiated thymidine or radiophosphate of myelocytes synthesizing DNA. Craddock, Perry, and Lawrence observed a maximal blood leukocyte specific activity 5 days after administering radiophosphate to dogs (18), and Patt and Maloney found a maximal grain count in blood segmented neutrophils 5 days after administering tritiated thymidine (19). Thus, three independent measurements of this transit time are available for dogs and are in agreement.

The duration of phase I + II multiplied by the GTR (effective output of marrow granulocytes per day) measures the size of the marrow myelocyte pool plus the postmitotic pool. The figure derived from this calculation, $14.4 \times 10^{9}$ granu- locytes per $\mathrm{kg}$, is in good agreement with Alexanian, McAlexander, and Donohue's figure of $12.0 \times 10^{9}$ granulocytes per $\mathrm{kg}$ extrapolated from the dog's total erythroid mass (20) as measured with iron ${ }^{59}(21)$.

Measurement in a single system of the size and transmit time of the myelocyte compartment, of the postmitotic marrow pool, and of the blood pool can lead to a better understanding of the kinetics of changes in blood granulocyte concentration. For example, an approximately equal degree of granulocytosis was sustained following recovery from VLB and with cortisone injection. However, the kinetics of these two situations differed markedly. The granulocytosis seen 14 days following VLB was characterized not only by an increase in the GTR but by an increase in marrow transit time as well, so that the number of cells in the marrow was three times normal. In contrast, the blood granulocytosis accompanying cortisone administration was unaccompanied by any significant change in GTR, marrow transit time, or marrow pool size.

The model describing normal granulopoiesis, which was derived from computer analyses of data obtained from labeling human subjects with $\mathrm{DFP}^{32}$, tritiated thymidine, and radioactive sodium phosphate (4), is shown in Figure 5. If this model is representative of granulopoiesis, it must also describe the changes in the BGSA curve that were induced herein by perturbing the granulocytic system. 
At least three morphologically distinguishable mitotic compartments are recognized in granulocyte production, the myeloblast compartment, promyelocyte compartment, and myelocyte compartment. One of the primary differences between the model portrayed in Figure 5 and the usual scheme proposed for granulocyte production is the type of mitosis taking place in the myelocyte compartment.

The classic scheme of granulocyte production incorporates a theoretic and morphologically unidentified stem cell compartment. The progeny of mitosis in the stem cell compartment may either mature and enter the myeloblast compartment or remain as stem cells. Under homeostatic conditions of granulocyte production, one-half of the progeny of stem cell mitosis matures and enters the myeloblast compartment, and one-half remains stem cells to perpetuate the system. Once a cell matures beyond the stem cell compartment, all subsequent mitoses are of a different type in which all progeny must mature and enter the next compartment. This scheme is depicted in Figure 6-A. In this scheme each stem cell mitosis usually results in one-half of the cells produced entering the next compartment, whereas a mitosis in subsequent compartments results in all cells produced entering the next compartment.

The scheme proposed herein (Figure 6-B) differs from the classic scheme (Figure 6-A) in that at any mitotic compartment level the progeny may remain in that compartment to divide again, or they may mature and enter the next compartment. It is proposed that in the myelocyte compartment, under homeostatic conditions, approximately one-half of the mitotic progeny matures and one-half remains in the myelocyte compartment to perpetuate the compartment. A compartment wherein all mitotic progeny must mature has been referred to previously as an "open" compartment, and a compartment wherein mitotic progeny may either mature or remain in the compartment has been referred to as a "semi-closed" compartment (4). It should be emphasized that the actual process of mitosis is the same in these compartments and that the subsequent behavior of the progeny determines the nature of the population.

The hypothesis of a myelocyte compartment that approaches self-perpetuation was formulated

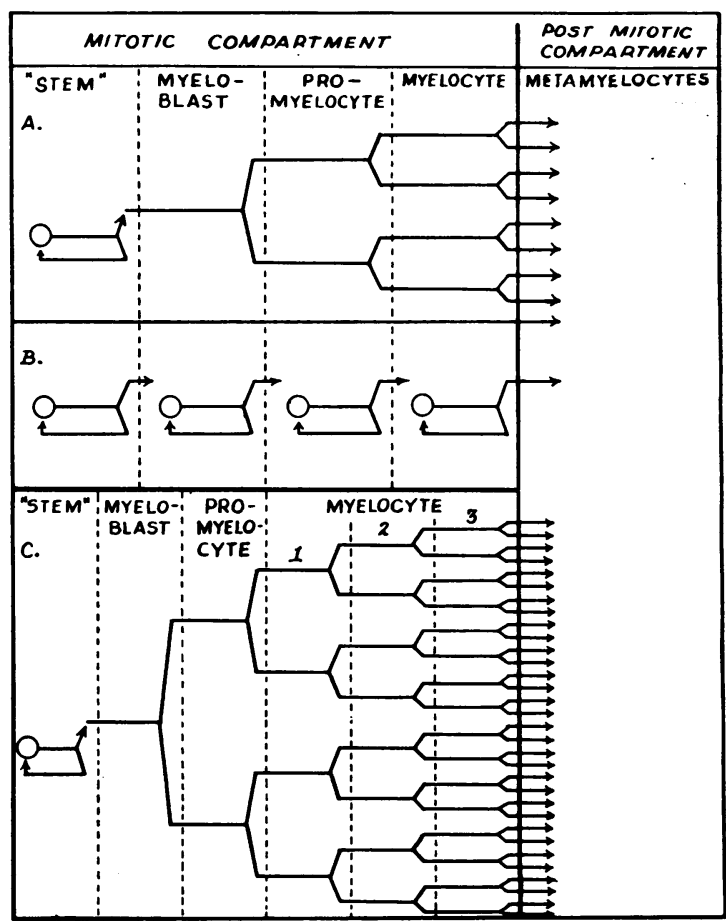

Fig. 6. Three schemes of Mitosis in MARROW COMPARTMENTS. The classic scheme that is usually assumed is illustrated in Figure 6-A. The hypothesis of a series of partially self-perpetuating mitotic compartments is illustrated in 6-B. A modified classic scheme that is also compatible with our data is illustrated in 6-C.

to explain the exponential slope of phase III of the BGSA curve in man (4) or dog. The slope of phase III would be uninfluenced by eradication of the myelocyte compartment if all postmitotic myelocytes matured as shown in Figure 6-A. Since marked reduction of the myelocyte compartment with VLB shortened the $t_{1}$ of phase III, it is apparent that phase III is influenced by the myelocyte compartment. Therefore, our data are not compatible with the scheme depicted in Figure 6-A. However, if the number of mitotic compartments is expanded to include at least three such compartments within the morphologic boundaries of the myelocyte compartment, then a scheme other than a self-perpetuating myelocyte compartment is compatible with our data (Figure 6-C).

Killmann and co-workers (22) have emphasized a further unknown with respect to the type of mitosis taking place in various compartments. They termed a myelocyte mitosis that results in 
the formation of two myelocytes which must then mature in order to leave the compartment, "homomorphogenic" division, and a myelocyte mitosis that results in the postmitotic appearance of two metamyelocytes, "heteromorphogenic" division. If heteromorphogenic mitosis exists, then mitosis in our self-perpetuating myelocyte compartment would be an asymmetric mitosis, that is, at the completion of a myelocyte mitosis one of the progeny would be a metamyelocyte and the other a myelocyte. Although either homomorphogenic or heteromorphogenic mitosis will fit our data, we have illustrated homomorphogenic mitosis in the models portrayed in Figures 5 and 6 .

A myelocyte compartment approaching selfperpetuation is an unproven hypothesis. However, this hypothesis represents the simplest model that will explain the exponential slope of phase III in the BGSA curve. This model is compatible with the labeling curves observed following administration of $\mathrm{H}^{3}$-thymidine or radiophosphate as leukocyte labels (4) and will account for the "lost" myelocytes in the "myelocyte-sink" proposed by Patt and Maloney (2). Furthermore, with the series of compartments approaching selfperpetuation depicted in Figure 6-B, the difficulty in demonstrating a fixed myeloblast to promyelocyte to myelocyte ratio (22) is obviated. If the assumption that promyelocytes and myeloblasts are precursors of myelocytes is correct, then these compartments can be considered reserve compartments from which the granulocytic system can be enlarged rapidly or from which lost myelocytes are replaced rapidly.

Assuming that the model in Figure 6-B or in Figure 6-C is correct, then the slope contributed to phase III by the myelocyte defines the myelocyte generation time. Myelocyte generation time so measured lies between 18 and 25 hours depending upon what assumption is adopted for subtracting phase IV from phase III. Lala, Maloney, and Patt (23) measured the generation time for myelocytes in dogs by means of tritiated thymidine labeling and mitotic indexes and found it to lie between 10 and 19 hours.

The accelerated slope of phase III observed in infection, after endotoxin, and following recovery from VLB as well as the inverse correlation of the slope of phase III with the duration of phase I + II in normal dogs deserves com- ment. Interpretation of these changes is complicated, since details of the kinetic perturbation in these circumstances are less clearly defined than in the myelocyte ablation studies. A comprehensive explanation for these phase III changes was sought by entertaining hypotheses that included a changing myelocyte generation time, skipped myelocyte mitoses, a random release marrow storage pool, and return of cells to blood and marrow.

An accelerated myelocyte generation time or skipped myelocyte mitosis could explain the phase III change observed in infection and during hypertrophy following VLB, but could not explain the similar phase III change observed when $\mathrm{DFP}^{32}$ was given with or 2 days following endotoxin administration. A random release storage pool is compatible with the phase III change observed with endotoxin and with infection but not with that observed during hypertrophy following VLB. Furthermore, if there were a random release storage pool, a direct relationship between phase II and phase III should have been observed in studies of normal dogs rather than the inverse relationship found. Return of cells to blood or to marrow is incompatible with all of the observations in the perturbed system. None of these hypotheses was tenable as an explanation for the observed slope of phase III in all of the different studies.

The following hypothesis is compatible with all of the observed changes in the slope of phase III. The postmitotic marrow pool is a first-in first-out kinetic system (Figure 5). Under normal circumstances segmented neutrophils are preferentially released to the blood, but juvenile neutrophils are released if segmented neutrophils are not readily available. The limited number of segmented neutrophils in dog marrow (5\% of granulocytic cells) leads to a variation in marrow transit since a segmented neutrophil is older than a juvenile neutrophil (24). An 8-hour standard deviation about the mean transit time through the postmitotic compartment will explain the portion of the phase III slope in normal dogs that was not accounted for by the myelocyte generation time and the blood transit time. As the marrow storage pool increases in size, the relative number of juvenile neutrophils released decreases so that an approximate age cohort of segmented neutrophils is released and transit time variation is 
reduced. This explains the inverse correlation of the slope of phase III with the duration of phase I + II in normal dogs as well as the reduced $t_{t}$ in the hypertrophied system following recovery from VLB. Exhaustion of the reserve of segmented neutrophils also reduces the variation about the mean transit time, since under these circumstances juvenile neutrophils, again approximating an age cohort, are released to the blood. This explains the accelerated phase III observed with infection and after endotoxin.

\section{Summary}

This study was undertaken to evaluate previously published kinetic interpretations of the blood granulocyte specific activity (BGSA) curve obtained from labeling human granulocytes with intravenously administered radioactive diisopropyl fluorophosphate $\left(\mathrm{DFP}^{32}\right)$.

Dogs were given $\mathrm{DFP}^{32}$ intravenously, and a four-phase curve of BGSA was observed. The BGSA declined $20 \%$ during the first day (phase I) and then remained relatively stable, declining only $2 \%$ per day, until the fifth day (phase II). An exponential decline in BGSA then supervened (phase III) and was in turn succeeded by a final, slowly declining curve (phase IV).

The BGSA curve in normal dogs was contrasted with that observed when the granulopoietic system was perturbed by the administration of vinblastine sulfate, endotoxin, or cortisone or by the development of infection. A marked reduction of marrow mitotic cells by VLB was associated with a shortened phase I + II and an increased slope of phase III. Hypertrophy of the granulocytic system accompanied recovery from VLB administration and was associated with an increase in the duration of phase I + II and an increase in the slope of phase III. Acceleration of mature granulocyte release from the bone marrow by administering endotoxin was associated with a shortened phase I + II and an increased slope of phase III. Blood granulocytosis induced by cortisone produced no change in the blood granulocyte turnover rate and was not associated with any change in the BGSA curve. Pulmonary infection, accompanied by blood granulocytosis, was associated with a shortened phase I + II and an increased slope of phase III. None of these situations was associated with any significant change in the characteristics of phase IV.

From these studies and studies of initial labeling conditions, the following interpretation of each of the four phases of the BGSA curve was derived. Phase I represents replacement of cells that were in the blood when $\mathrm{DFP}^{32}$ was given, by marrow cells with a lesser degree of labeling. Phase II represents the sequential delivery to the blood of marrow cells that were in the postmitotic pool when $\mathrm{DFP}^{32}$ was given as well as the progeny of the first myelocyte generation after labeling. Phase III reflects dilution of the label by the results of mitosis. Its slope is determined by at least three factors: the myelocyte generation time, the variation in transit time through the postmitotic marrow compartment, and the blood transit time. Phase IV probably represents reutilization of a metabolite of $\mathrm{DFP}^{32}$-labeled enzymes.

A model of granulopoiesis that adequately describes the data presented consists of the following. Myelocytes are to a degree self-perpetuating; that is, one-half of the progeny of myelocyte mitosis may remain myelocytes and divide again, thus perpetuating the compartment, whereas the other one-half may mature. The postmitotic maturation and storage compartment of the marrow operates primarily as an orderly first-in first-out kinetic system. Granulocytes leave the blood primarily through random loss, and the entire system is unidirectional.

\section{Acknowledgments}

We are grateful to Miss Helen Ashenbrucker for technical assistance and to $\mathrm{Mr}$. George Trappett and $\mathrm{Mr}$. Dale Chlarson for their animal husbandry. We are indebted to Dr. J. G. Armstrong of the Eli Lilly Research Laboratories for the vinblastine sulfate, to Dr. E. Alpert of the Merck Sharp \& Dohme Research Laboratories for the cortisone acetate, and to Dr. F. H. Schultz of the Wander Company for the endotoxin (Lipexal).

\section{References}

1. Cronkite, E. P., and T. M. Fliedner. Granulopoiesis. New Engl. J. Med. 1964, 270, 1347, 1403.

2. Patt, H. M., and M. A. Maloney. A model of granulocyte kinetics. Ann. N. Y. Acad. Sci. 1964, 113, 515.

3. Craddock, C. G., Jr. The physiology of granulocytic cells in normal and leukemic states. Amer. J. Med. 1960, 28, 711. 
4. Warner, H. R., and J. W. Athens. An analysis of granulocyte kinetics in blood and bone marrow. Ann. N. Y. Acad. Sci. 1964, 113, 523.

5. Raab, S. O., J. W. Athens, O. P. Haab, D. R. Boggs, H. Ashenbrucker, G. E. Cartwright, and M. M. Wintrobe. Granulokinetics in normal dogs. Amer. J. Physiol. 1964, 206, 83.

6. Athens, J. W., A. M. Mauer, H. Ashenbrucker, G. E. Cartwright, and M. M. Wintrobe. Leukokinetic studies. I. A method for labeling leukocytes with diisopropylfluorophosphate $\left(\mathrm{DFP}^{32}\right)$. Blood 1959, 14, 303.

7. Folch, J., M. Lees, and G. H. S. Stanley. A simple method for the isolation and purification of total lipides from animal tissues. J. biol. Chem. 1957, 226, 497.

8. Jandorf, B. J., and P. D. McNamara. Distribution of radiophosphorus in rabbit tissues after injection of phosphorus-labeled diisopropyl-fluorophosphate. J. Pharmacol. exp. Ther. 1950, 98, 77.

9. Boggs, D. R., J. W. Athens, O. P. Haab, P. A. Cancilla, S. O. Raab, G. E. Cartwright, and M. M. Wintrobe. Leukokinetic studies. VII. Morphology of the bone marrow and blood of dogs given vinblastine sulfate. Blood 1964, 23, 53.

10. Athens, J. W., O. P. Haab, S. O. Raab, A. M. Mauer, H. Ashenbrucker, G. E. Cartwright, and M. M. Wintrobe. Leukokinetic studies. IV. The total blood, circulating and marginal granulocyte pools and the granulocyte turnover rate in normal subjects. J. clin. Invest. 1961, 40, 989.

11. Kurth, D., J. W. Athens, E. P. Cronkite, G. E. Cartwright, and M. M. Wintrobe. Leukokinetic studies. V. Uptake of tritiated diisopropylfluorophosphate by leukocytes. Proc. Soc. exp. Biol. (N. Y.) 1961, 107, 422.

12. Craddock, C. G., Jr., S. Perry, L. E. Ventzke, and J. S. Lawrence. Evaluation of marrow granulocytic reserves in normal and disease states. Blood $1960,15,840$.

13. Plapp, F. W., and J. E. Casida. Hydrolysis of the alkylphosphate bond in certain dialkyl aryl phosphorothioate insecticides by rats, cockroaches, and alkali. J. econ. Entom. 1958, 51, 800.
14. Nemer, M. J., and D. Elwyn. The conversion of serine to ethanolamine and its derivatives in the rat. J. biol. Chem. 1960, 235, 2070.

15. Mizuno, N. S., V. Perman, F. W. Bates, J. H. Sautter, and M. O. Schultz. Life span of thrombocytes and erythrocytes in normal and thrombocytopenic calves. Blood 1959, 14, 708.

16. Cartwright, G. E., J. W. Athens, and M. M. Wintrobe. The kinetics of granulopoiesis in normal man. Blood 1964, 24, 780.

17. Byrne, W. L. Glucose 6-phosphatase and phosphoserine phosphatase in The Enzymes, 2nd ed., P. D. Boyer, H. Lardy, and K. Myrback, Eds. New York and London, Academic Press, 1961, vol. 5, p. 73.

18. Craddock, C. G., S. Perry, and J. S. Lawrence. The dynamics of leukopoiesis and leukocytosis, as studied by leukopheresis and isotopic techniques. J. clin. Invest. 1956, 35, 285.

19. Patt, H. M., and M. A. Maloney. Kinetics of neutrophil balance in The Kinetics of Cellular Proliferation, F. Stohlman, Jr., Ed. New York and London, Grune \& Stratton, 1959, p. 201.

20. Alexanian, R., R. McAlexander, and D. Donohue. Effect of splenectomy upon bone marrow cellularity in the dog. Clin. Res. 1965, 13, 38.

21. Donohue, D. M., R. H. Reiff, M. L. Hanson, Y. Betson, and C. A. Finch. Quantitative measurement of the erythrocytic and granulocytic cells of the marrow and blood. J. clin. Invest. 1958, 37, 1571.

22. Killmann, S-Å., E. P. Cronkite, T. M. Fliedner, V. P. Bond, and G. Brecher. Mitotic indices of human bone marrow cells. II. The use of mitotic indices for estimation of time parameters of proliferation in serially connected multiplicative cellular compartments. Blood 1963, 21, 141.

23. Lala, P. K., M. A. Maloney, and H. M. Patt. A comparison of two markers of cell proliferation in bone marrow. Acta haemat. (Basel) 1964, 31, 1.

24. Bond, V. P., T. M. Fliedner, E. P. Cronkite, J. R. Rubini, and J. S. Robertson. Cell turnover in blood and blood forming tissues studied with tritiated thymidine in The Kinetics of Cellular Proliferation, F. Stohlman, Jr., Ed. New York and London, Grune \& Stratton, 1959, p. 188. 